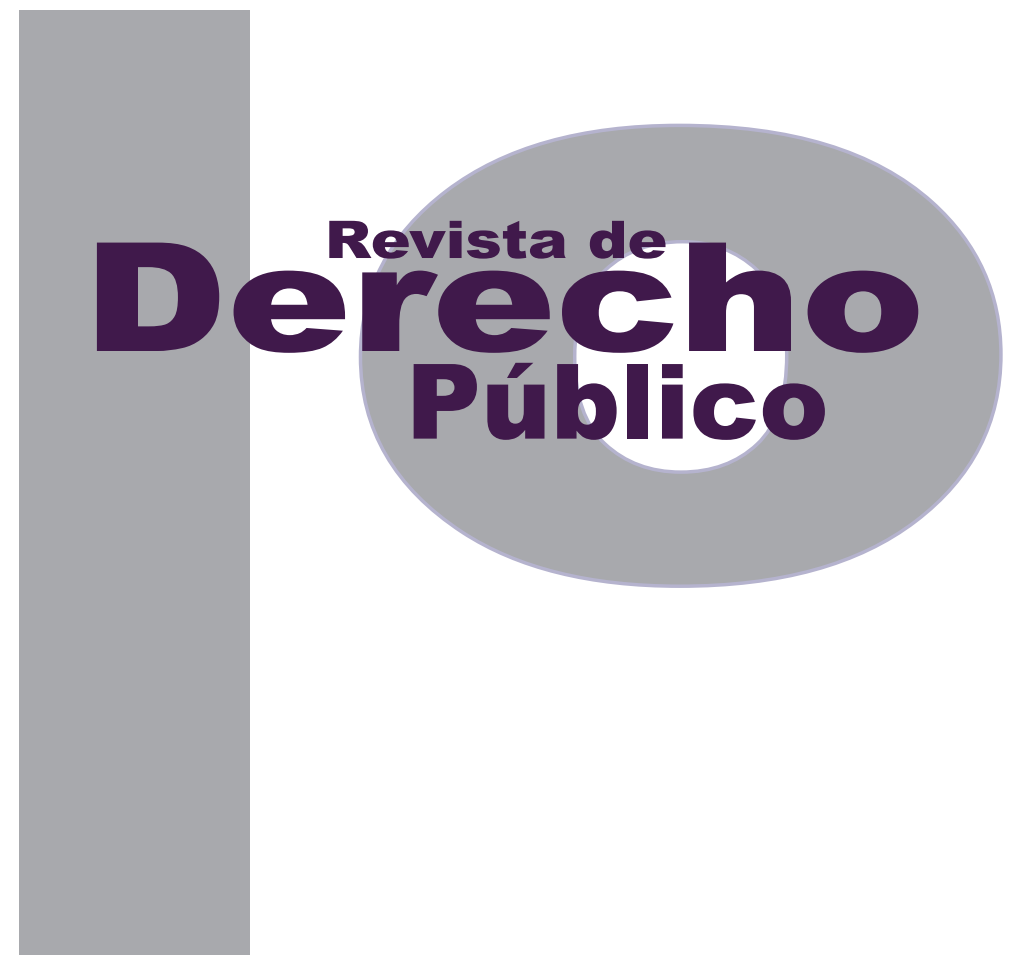

\title{
EL CONTRATO SUI GENERIS DE AMIGABLE COMPOSICIÓN: UNA ALTERNATIVA PARA LA SOLUCIÓN DE CONTROVERSIAS EN LOS PROYECTOS DE INFRAESTRUCTURA
}

\author{
Tatiana OÑate Acosta \\ Francisco TERnERA BARRIOS \\ Artículo de reflexión \\ DOI: http://dx.doi.org/10.15425/redepub.35.2015.03 \\ Universidad de los Andes \\ Facultad de Derecho \\ Rev. derecho publico No.35 \\ julio - diciembre de 2015. ISSN 1909-7778
}




\title{
El contrato sui generis de amigable composición: una alternativa para la solución de contro- versias en los proyectos de infraestructura
}

\section{Resumen}

En este breve ensayo nos ocuparemos de la amigable composición colombiana, una institución que es, a la vez, un contrato y un mecanismo alternativo de solución de conflictos, que como tal parece no tener mayores referentes en el mundo y que podría ofrecernos diversas bondades en la regulación de intercambios económicos, particularmente en lo que concierne a los proyectos de infraestructura. Como lo señala parte de la doctrina, no son muchos los temas de la teoría del derecho que se producen o se desarrollan en Latinoamérica de una manera autónoma y original. He aquí un contrato que tiene un régimen especial aplicable (López, 2004). Desde esta perspectiva, los proyectos de infraestructura se convierten en el terreno ideal para que las especiales características que identifican la amigable composición colombiana faciliten la solución de los conflictos que se pueden presentar en la gestión contractual de estas operaciones.

Palabras clave: conflictos, amigable composición, proyectos de infraestructura, representación.

\section{The sui generis contract of friendly dispute resolution: an alternative for resolving disputes in infrastructure projects}

\begin{abstract}
This brief essay discusses a form of friendly dispute resolution known in Colombia as the amigable composición, which is an institution that is a contract as well as an alternative dispute resolution mechanism. A similar type of resolution mechanism does not seem to be available anywhere else in the world and could offer a range of benefits in the regulation of economic exchanges, particularly with regard to infrastructure projects. As part of the doctrine indicates, there are few issues involving legal theory that are developed independently and originally in Latin America. The contract addressed here has a special scheme (Lopez, 2004). From this perspective, infrastructure projects become the ideal field for the special characteristics that make up Colombia's amigable composición and facilitate a resolution to conflicts that may arise in the contractual management of these operations.
\end{abstract}

Keywords: conflicts, amigable composición, infrastructure projects, representation, friendly dispute resolution.

\section{O contrato sui generis de composição amigável: uma alternativa para a solução de contro- vérsias nos projetos de infraestrutura}

\section{Resumo}

Neste breve ensaio nos ocuparemos da composição amigável colombiana, uma instituição que é, ao mesmo tempo, um contrato e um mecanismo alternativo de solução de conflitos, que como tal parece não ter maiores referentes no mundo e que poderia oferecer-nos diversas bondades na regulamentação de intercâmbios econômicos, particularmente no que concerne aos projetos de infraestrutura. Como mostra parte da doutrina, não são muitos os temas da teoria do direito que se produzem ou se desenvolvem na América Latina de uma maneira autônoma e original. Eis aqui um contrato que tem um regime especial aplicável (López, 2004). Desde esta perspectiva, os projetos de infraestrutura se transformam no terreno ideal para que as características especiais que identificam a composição amigável colombiana facilitem a solução dos conflitos que se podem apresentar na gestão contratual destas operações.

Palavras-chave: conflitos, composição amigável, projetos de infraestrutura, representação. 


\title{
El contrato sui generis de amigable composición: una alternativa para la solución de controversias en los proyectos de infraestructura*
}

\author{
Tatiana Oñate Acosta \\ Francisco Ternera Barrios
}

\section{SUMARIO}

Introducción - I. CONSAGRACIÓN DE LA AMIGABLE COMPOSICIÓN EN EL UNIVERSO JURÍDICO: UNA MISMA EXPRESIÓN Y TRES INSTITUCIONES DISTINTAS - A. La amigable composición como arbitraje - B. La amigable composición como una conciliación - C. La amigable composición como mecanismo heterocompositivo: la institución consagrada en la Ley 1563 de 2012-II. LA NATURALEZA CONTRACTUAL DE LA AMIGABLE COMPOSICIÓN COLOMBIANA - A. Rasgos comunes con el mandato - 1. Formación de los convenios - 2. Ejecución de los convenios - B. Particularidades de la amigable composición - 1. Sobre los mandantes-querellantes - 2. Sobre el mandatario-componedor - 3. Sobre el desarrollo de la composición - III. CONCLUSIONES - Referencias.

* Cómo citar este artículo: Oñate Acosta, T. y Ternera Barrios, F. (Diciembre, 2015). El contrato sui generis de amigable composición: el resurgimiento de una alternativa para la solución de controversias en los proyectos de infraestructura. Revista de Derecho Público, 35. Universidad de los Andes (Colombia).

Este artículo de reflexión presenta, desde una perspectiva analítica, los resultados de la investigación terminada sobre mecanismos alternativos de solución de controversias, realizada en el marco del proyecto "Las vías alternas para solucionar conflictos", entre el mes de septiembre de 2013 y cerrada, precisamente, con este ensayo.

Los autores son investigadores de la línea de Arbitraje del grupo de investigaciones en Derecho Privado de la Facultad de Jurisprudencia de la Universidad del Rosario, institución que financia el proyecto.

** Profesora principal de la Facultad de Jurisprudencia de la Universidad del Rosario (Colombia).

*** Profesor titular de la Facultad de Jurisprudencia de la Universidad del Rosario (Colombia). 
Introducción

En Colombia, hasta hace poco tiempo, la amigable composición, el mecanismo de solución de controversias por el cual se delega en un tercero -el amigable componedor - la facultad de definir, con fuerza vinculante para las partes, una controversia contractual de libre disposición, fue considerada una figura vetada para las entidades estatales. Por lo tanto, era ajena a los contratos estatales.

En efecto, a pesar de que el artículo 68 de la Ley 80 de 1993 consagraba expresamente que las entidades estatales podían recurrir a esta figura, ${ }^{1}$ un llamativo y profundo concepto de la Sala de Consulta y Servicio Civil del Consejo de Estado, con ponencia del magistrado Enrique José Arboleda Perdomo, consideró que, a partir del artículo 130 de la Ley 446 de 1998, la amigable composición solo era aplicable por particulares y no por entidades estatales y que, en consecuencia, el artículo 68 de la Ley 80 de 1993 estaba derogado parcialmente.

Sin embargo, a pesar de que los conceptos del Consejo de Estado (CE) no son vinculantes, las circunstancias especiales del caso concreto relacionado con uno de los contratos más importantes de los últimos años para el desarrollo de la infraestructura del país $-^{2}$ impusieron la

1 Además, el artículo 69 de la misma ley determinó que las autoridades no podrían establecer prohibiciones para la utilización de los mecanismos de solución directa de las controversias surgidas de contratos estatales.

2 El concepto del Consejo de Estado, Sala de Consulta y Servicio Civil, de 13 de agosto de 2009, con ponencia del consejero Enrique José Arboleda Perdomo, radicación n. ${ }^{\circ} 1952$, se emitió como consecuen- siguiente consecuencia práctica: en los proyectos de infraestructura no se podía recurrir a este mecanismo de solución de controversias.

Sobre el particular, valga aclarar lo siguiente. Por proyectos de infraestructura entendemos el conjunto de acuerdos y contratos entre varias partes, incluyendo al Gobierno como regulador o concesionario, con el fin de desarrollar los insumos de capital fundamentales para la producción y generación de riqueza considerados elementos necesarios en todas las etapas de desarrollo de las economías (Lardé y Sánchez, 2014). En este sentido, tomamos partido por la posición que considera que la infraestructura puede tener un impacto transformador, favoreciendo la productividad y la competitividad en los mercados internacionales, y con ello el crecimiento y el desarrollo económico y social (Lardé y Sánchez, 2014).

En términos generales, la literatura económica ha estimado que los servicios en red de la infraestructura energética, de transporte, telecomunicaciones, agua potable y saneamiento constituyen un elemento articulador de la estructura económica de los territorios y sus mercados, y son mecanismos concretos de acoplamiento de las economías nacionales con el resto del mundo, haciendo posible la movilidad de carga y de pasajeros y las transacciones dentro de un espacio geográfico y económico determi-

cia de una consulta realizada por el Ministerio de Transporte frente al Contrato n. ${ }^{\circ} 6000169 \mathrm{OK}$ del 12 de septiembre de 2006, suscrito entre la Aeronáutica Civil y el Concesionario OPAIN S. A., cuyo objeto es la concesión para la administración, operación, explotación comercial, mantenimiento, modernización y expansión del aeropuerto internacional El Dorado, de la ciudad de Bogotá, D. C. 
nado, y con el exterior. Por esta razón, en los últimos años los países en desarrollo han fomentado la realización de reformas que permitan mejorar y extender los servicios de infraestructura, al ser conscientes de que los niveles y la calidad de esta tienen un enorme efecto sobre el crecimiento económico y la disminución de la pobreza, y que los niveles de calidad actuales son inadecuados.

Particularmente, desde hace algunas décadas, los proyectos de infraestructura se han impulsado gracias a la participación privada, la cual ha sido motivada por una necesidad urgente de realizar enormes inversiones. En efecto, dada la escasez de fondos públicos y las necesidades en amplios sectores sociales, la mayoría de los países optaron por transferir los servicios de infraestructura al sector privado. Esta participación privada en los proyectos de infraestructura puede darse de diferentes formas, las cuales pueden involucrar desde los contratos de administración y de concesión en todas sus modalidades, hasta finalmente llegar a la privatización plena (Guasch, 2004). Desde esta perspectiva, en nuestro país, ${ }^{3}$ así como en México ${ }^{4}$ y Perú, ${ }^{5}$

3 Ver: Ley 1508 de 2012.

4 Ver: Ley de Asociaciones Público-Privadas del 16 de enero de 2012, reformada el 14 de julio de 2014.

5 Ver: Decreto Legislativo n. 1012 "que aprueba la Ley Marco de Asociaciones Público-Privadas para la generación de empleo productivo y dicta normas para la agilización de los procesos de promoción de la inversión privada" (actualizado al 02.03.2014)

Reglamento del Decreto Legislativo n. ${ }^{\circ} 1012$-Decreto Supremo n. ${ }^{\circ}$ 127-2014-EF- "Reglamento del Decreto Legislativo n. ${ }^{\circ} 1012$ que aprueba la Ley Marco de Asociaciones Público Privadas para la generación de empleo productivo y dicta normas para la agilización de los procesos de promoción de la inversión privada."

Decreto Supremo n. ${ }^{\circ}$ 376-2014-EF, "Modifican el Reglamento del Decreto Legislativo n. ${ }^{\circ}$ 1012, que aprueba la Ley Marco de la tendencia reciente es estimular el desarrollo de proyectos de infraestructura a través de las llamadas asociaciones público-privadas (APP). Esta figura que, en principio, parecería darle un nuevo ropaje a la participación privada en los proyectos de infraestructura, según Vasallo e Izquierdo de Bartolomé (2010) se caracteriza porque la relación entre el sector público y el sector privado tiene una larga duración y hay una adecuada distribución de riesgos entre ellos; además, el sector privado participa de algún modo en la financiación y debe tener un papel fundamental en el mantenimiento y explotación de la infraestructura, y su fundamento es "prestar un servicio de calidad a los usuarios al menor costo posible" (pág. 104).

Dada la complejidad de estos proyectos, asociada generalmente a las asimetrías de la información y las circunstancias externas que pueden afectar su ejecución, tener un mecanismo idóneo que permita, de una parte, que la entidad estatal pueda contar a tiempo con la infraestructura operando al servicio de la comunidad, al costo esperado, sin tener que acudir a procesos judiciales interminables y, por otra parte, que el particular pueda tener una solución eficaz en tiempo real a sus problemas para evitar que las posibles demoras se conviertan en sobrecostos del proyecto como consecuencia del mayor riesgo que debe asumir, no es algo meramente accesorio o circunstancial. Por el contrario, el mecanismo de solución de diferencias que se acoja en el marco de estos proyectos se convier-

\footnotetext{
Asociaciones Público Privadas para la Generación del Empleo Productivo y dicta Normas para la Agilización de los Procesos de Promoción de la Inversión Privada, aprobado mediante Decreto Supremo n. ${ }^{\circ}$ 127-2014-EF."
}

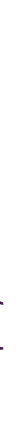


te en un elemento fundamental para asegurar su éxito o fracaso, ya que no se trata solamente de mitigar el riesgo legal, puesto que en la mayoría de los casos la controversia involucra riesgos adicionales tales como los comerciales, ambientales y políticos que pueden amenazar la continuidad del proyecto.

En este contexto, una de las ventajas para el desarrollo de los proyectos de infraestructura en el país es que, en la actualidad, la Ley 1563 de 2012 establece expresamente que las entidades públicas o quien desempeñe funciones administrativas al igual que los particulares pueden acudir al mecanismo de la amigable composición. En ese sentido, el artículo $2^{\circ}$ de la Ley 1742 del 26 de diciembre de 2014 "por la cual se adoptan medidas y disposiciones para los proyectos de infraestructura de transporte, agua potable y saneamiento básico, y los demás sectores que requieran expropiación en proyectos de inversión que adelante el Estado y se dictan otras disposiciones" modificó el literal "a" del artículo 14 de la Ley 1682 de 2013, con el fin de precisar que "las decisiones proferidas en ejercicio de los mecanismos alternativos de solución de controversias relativas al contrato, deberán proferirse en derecho, salvo en el evento de la amigable composición en el que la decisión podrá adoptarse en equidad, de conformidad con el artículo 60 de la Ley 1563 de 2012."

Desde esta perspectiva, la investigación adelantada busca evidenciar que con la creación y reglamentación legal de la amigable composición en el derecho colombiano, parecería haberse generado una institución jurídica propia en el marco de los mecanismos alternativos de solución de controversias (MASC). En efecto, hoy en día, después de dos siglos de recorrido normativo, la institución cuenta con un régimen especial consagrado en la Ley 1563 de 2012, grosso modo, como una transacción adoptada e impuesta por un tercero a dos querellantes. Por lo demás, para desarrollar su misión, este tercero se encuentra investido con una doble representación: la de los dos pleiteantes.

En estas líneas nos proponemos responder preguntas tales como las siguientes: ¿Cómo se ha consagrado en las diferentes normativas la figura? ¿Se trata de una simple variedad del contrato de arbitraje? ¿Cuáles referencias normativas podrían citarse? ¿Cuál es el concepto de la amigable composición consagrada en la Ley 1563 de 2012? ¿Dado que su régimen sigue siendo muy discreto, cuáles regímenes especiales podrían extenderse a la actual institución?

Desde esta óptica, nos concentraremos en dos ejes centrales:

- La consagración de la amigable composición en las diferentes normativas internacionales y domésticas, y

- Su proximidad con el contrato especial de mandato, para el caso de la amigable composición doméstica. 


\section{CONSAGRACIÓN DE LA AMIGABLE COMPOSICIÓN EN EL UNIVERSO JURÍ- DICO: UNA MISMA EXPRESIÓN Y TRES INSTITUCIONES DISTINTAS}

La expresión amigable composición ha tenido diferentes lecturas en el mundo y en el país. Así las cosas, la institución in examine -la amigable composición- en Colombia se enfrenta a un problema de homonimia: con las mismas palabras se designan tres instrumentos totalmente diferentes: como arbitraje, como conciliación y como mecanismo heterocompositivo.

\section{A. La amigable composición como arbitraje}

Como primera medida vale la pena dar un vistazo a nuestra figura en el contexto mundial. Por ejemplo, podríamos preguntarnos lo siguiente: ¿la expresión amigable composición es desconocida en las normativas mundiales? Desde luego que no; este binomio de palabras tiene asiento en decenas de ellas. Sin embargo, aclaramos que con esta expresión se hace referencia a nuestro arbitraje en equidad o árbitro ex aequo et bono: un verdadero arbitramento cuyo laudo o sentencia se dicta conforme a los postulados de la equidad o la conciencia. En la doctrina se explica así:

El arbitraje puede ser de derecho o de equidad. En el primero los árbitros deben juzgar según las reglas de derecho. En el segundo, que se denomina generalmente amigable composición, los árbitros juzgan en equidad, sin tener en cuenta los preceptos legales con la sola li- mitación de las disposiciones de orden público (De Sola Cañizares, 1962, pág. 531).

Sobre el particular, a manera de ejemplo, podrían citarse el artículo 28.3 del Procedimiento para solución de disputas internacionales - International Dispute Resolution Procedures- de la American Arbitration Association (AAA), el artículo 21 del Reglamento de la Cámara de Comercio Internacional (ccl), el artículo 28.3 de la Ley-modelo para el Arbitraje Comercial Internacional, el artículo 33.2 del Reglamento de Arbitraje de la Comisión de las Naciones Unidas para el Derecho Mercantil Internacional (CNUDMI), el artículo VII de la Convención Europea del 21 de abril de 1961, el artículo 59 del Reglamento de Arbitraje de la Organización Mundial de la Propiedad Intelectual (ompI), entre otros.

También en las diferentes normativas domésticas mundiales se establece lo siguiente: el amigable componedor, arbitrado o árbitro ex aequo et bono profiere su laudo de acuerdo con los fundamentos de la equidad -que no del derecho-.

Al respecto pueden consultarse decenas de normas, entre ellas las siguientes: el art. 1438 del Código Judicial de Panamá, el art. 223 del Código Orgánico de Tribunales y el art. 636 del Código de Procedimiento Civil de Chile, el art. 959 del Código de Procedimiento Civil de Nicaragua, el art. 1019 del Código de Procedimiento Civil de República Dominicana, el art. 34 de la Ley 60/2003 de 23 de diciembre de España, el art. 32 de la Ley 1879 de 2002 de Paraguay, el art. 766 del Código Procesal Civil y Comercial de Argentina y el art. 804 del Código Procesal de 
la Provincia de Buenos Aires, y el art. 1478 del Código de procedimiento Civil de Francia.

En una palabra, este mecanismo denominado en los sistemas jurídicos foráneos amigable composición es un verdadero arbitramento, más exactamente un arbitraje en equidad. Como se sabe, el arbitraje es un mecanismo alternativo de solución de conflictos (Venegas, 2005).

Con él, los querellantes defieren a árbitros la solución de una controversia relativa a asuntos de libre disposición (CConst., C-098/01, M. Sáchica). Sin importar su modalidad, en derecho, técnico o en equidad (art. 1 de la Ley 1563 de 2012), o bien ad hoc o institucional (art. 1 de la Ley 1563 de 2012), el arbitraje es siempre un mecanismo jurisdiccional: la solución se materializa con una sentencia o laudo.

He aquí una curiosa transformación de la fisonomía del arbitramento: nace con ropajes contractuales -el pacto arbitral (art. 3 de la Ley 1563 de 2012)- y se desarrolla y muere en un escenario estrictamente jurisdiccional: los árbitros administran justicia y se someten a las normas procesales como cualquier otro juez de la República (art. $116 \mathrm{cN}$ ).

\section{B. La amigable composición como una conciliación}

Como segunda medida, en ciertas Constituciones de la Patria Boba y leyes republicanas -al igual que los instrumentos foráneos comentados-, la composición equivalía a una conciliación: el tercero componedor simplemente proponía fórmulas de arreglo, que podían ser aceptadas o rechazadas por los querellantes (Restrepo, 1996).

Por ejemplo, en la Constitución de Mariquita, del 24 de junio de 1815, se aclaraba que los "jueces mayores de paz" podían fungir como componedores de transacción y conciliaciones (título 17 ídem). También en la Constitución de Neiva, del 31 de agosto de 1815, se establecía el procedimiento de amistosa transacción. La fórmula era la siguiente:

Los Alcaldes ordinarios no deben admitir demanda o queja alguna por escrito sin que primero hayan hecho comparecer ante sí, y a presencia del escribano, las partes contendoras y sus abogados o defensores, si quisieren traerlos. El actor expondrá su demanda, y el demandado la contestará, y después de conferenciadas las acciones y excepciones con los documentos o razones en que funde cada cual su intención procurará el Juez reducirlos a concordia o amistosa transacción, sentándose de todo por el escribano circunstanciada diligencia, que será principio del proceso en caso de no avenirse las partes, o de que la naturaleza del pleito no lo permita; y la falta de esta diligencia inducirá nulidad en todo lo que se actuare sin ella (Constitución de Neiva. Título VI. Del Poder Judicial; Sección Primera. De algunas disposiciones relativas al poder judicial y a la administración de justicia).

Por otro lado, también el legislador decimonónico reconoció al mecanismo como una simple conciliación. La fórmula acuñada en el art. 6 de la Ley 105 de 1890 fue la siguiente: “Los Jueces usarán, tanto respecto del demandado como 
del demandante, los apremios que establece el artículo 334 de esta ley, para que se surta la conferencia amigable."

\section{La amigable composición como mecanismo heterocompositivo: la institución consagrada en la Ley 1563 de 2012}

En tercer término, el legislador colombiano propuso las bases de la figura heterocompositiva que hoy denominamos amigable composición. Bien entrado el siglo xx, el legislador doméstico propuso un progreso brutal de la fisonomía del mecanismo: a partir de 1931 el componedor decidiría la disputa. La hipótesis era, sin embargo, bastante casuista: los procesos divisorios de inmuebles.

De manera concreta, se estableció en la Ley 105 de 1931 -Código Judicial- que tales divisiones inmobiliarias se confiaban a tres árbitros. Dentro de las prerrogativas de estos árbitros se encontraban: establecer transacciones o amigables composiciones. En el art. 1167 ídem se determinaba lo siguiente:

Son atribuciones de los árbitros: (...) 3. Conciliar, y si esto no fuere posible, decidir las opuestas pretensiones de los comuneros, y emplear los medios que, a su juicio, puedan dar por resultado una transacción o composición amigable, caso de que entre estos y los colindantes se susciten cuestiones sobre límites [cursivas propias].

En este mismo sentido, pero con un espectro más general, en el art. 677 del Decreto-Ley
1400 de 1970 -a la sazón el Código de Procedimiento Civil- se estableció lo siguiente: "En los casos previstos en el inciso primero del artículo 663, podrán los interesados someter sus diferencias a amigables componedores; la declaración de estos tiene valor contractual entre aquellos, pero no producirá efectos del laudo arbitral." Valga aclarar que en dicho inciso del art. 663 ídem se establecía lo siguiente: "Pueden someterse a la decisión de árbitros las controversias susceptibles de transacción que surjan entre personas capaces de transigir." En una palabra, se identifica a la amigable composición como un arbitraje puramente contractual.

Por su parte, ya en el art. 51 del Decreto 2279 de 1989 se afirmaba de manera categórica: “Por la amigable composición se otorga a los componedores la facultad de precisar, con fuerza vinculante para las partes, el estado y la forma de cumplimiento de una relación jurídica sustancial susceptible de transacción." Posteriormente, con los arts. 68 de la Ley 80 de 1993 y 130, 131 y 132 de la Ley 446 de 1998 -normas previas a la Ley 1563 de 2012-, se insistió en el carácter impositivo de la composición. ${ }^{6}$

Esta institución consagrada en la Ley 1563 de 2012 es eminentemente contractual (CConst., C-478/98, H. Sierra). A pesar de sus evidentes

6 De igual manera, textos como el art. 68 de la Ley 80 de 1993 también se han referido al mecanismo. Por otro lado, en la Ley 550 de 1999, que fue objeto de distintas modificaciones, se considera que el promotor de los acuerdos de reestructuración es un amigable componedor por ministerio de la ley (arts. 7,8, 23 y 25). Según la Circular Externa n. ${ }^{\circ} 04$ de 2001 de la Superintendencia de Sociedades, el promotor debe patrocinar el acercamiento de las partes, tratar que se presente el menor número posible de objeciones a la determinación de derechos de voto y acreencias y facilitar, siempre que sea viable, la adopción de una fórmula que permita la recuperación de la empresa. 
parecidos de familia con el arbitramento, la amigable composición propone profundas diferencias. Como lo afirma la doctrina, se trata de categorías autónomas, sujetas a reglas propias, amén que a un tratamiento disímil tanto en lo conceptual como en lo funcional (Jaramillo, 1998).

Efectivamente, los amigables componedores no ejercen función jurisdiccional alguna (CE Contencioso Administrativa, 6 feb. 1998, D. Suárez). ${ }^{7}$ Por el contrario, los árbitros -en derecho, técnicos o en equidad-, son siempre jueces. El amigable componedor es un apoderado. De allí que las recusaciones, en principio, sean posibles para el arbitraje e improcedentes para la amigable composición. En una palabra, la relación que surge entre el componedor y los mandantes es eminentemente contractual-privada: es un mandatario con doble representación (CConst., SU-091/00, Á. Tafur), mientras que en el arbitraje identificamos vínculos de estirpe procesal-pública.

Así mismo, la amigable composición culmina con un convenio de transacción -que no con un laudo-. Es decir, una vez terminada la misión del componedor, se yuxtaponen dos diferentes contratos: el mandato de amigable composición propiamente tal y el contrato de transacción. Por ello, el arreglo impuesto por el componedor no es susceptible de recurso alguno: no es una providencia. No obstante, procederían las accio-

7 De vieja data así lo tiene también establecido nuestra doctrina nacional: "la decisión de los amigables componedores no es nunca una sentencia sino, simplemente, un acto contractual, aquel cuya celebración se les encomendó para dar fin a la divergencia" (Gaviria, 1987). nes de nulidad y rescisión previstas en los arts. 2476-2483 cc. Tampoco, en principio, procedería acción de tutela alguna (CConst., T-153/10, J. Pretelt). Ahora bien, como cualquier otro contrato, la transacción puede ser objeto de nulidades y rescisiones (arts. 2478-2483 cc).

Para terminar, valdría la pena preguntarnos lo siguiente: ¿nuestra versión de amigable composición es verdaderamente original? Dicho en otros términos, ¿en el mundo existe alguna institución próxima a nuestro contrato de amigable composición?

Sobre el particular, en el contexto universal encontramos algunas figuras con ciertos parecidos de familia con nuestra amigable composición. Piénsese, por ejemplo, para el caso español, en la "intervención dirimente", la "mediación pericial" o el "arbitraje informal". ${ }^{8}$ De alguna manera, estas instituciones pudieron tener un soporte normativo en el derogado art. 367 cco. esp. Lo propio podría proponerse del instrumento galo intitulado expertise conventionnelle, mecanismo calcado del instituto romano denominado amicabilis compositor (Díez-Picazo, 1957). ${ }^{9}$

8 Véase Blanco Carrasco (2009). En las Partidas se ofrece esta misma lectura: los "comunales amigos" son escogidos por las partes y ayudan a unir y librar las contiendas. El texto es el siguiente: "arbitros en latín, tanto quiere decir, en romance, como Juezes auenidores, que son escogidos, e puestos de las partes, para librar la contienda, que es entre ellas. E estos son en dos maneras. La una es, quando los omes ponen sus pleytos e sus contiendas, en mano dellos, que los oyan, e los libres según derecho... La otra manera de juezes de auenencia es, a que llaman en latín Arbitratores, que quiere tanto dezir como aluedriadores, e comunales amigos, que son escogidos por anuencia de ambas partes, para auenir, e librar las contiendas que ouieren entre sí, en qualquier manera que ellos touieren por bien" (Partida 3. Título 4. Ley 23).

Sobre el amicabilis compositor véase Zimmermann (1996). 
En todos estos casos identificamos a un sujeto que presenta a las partes un proyecto de transacción o de arreglo. Son, pues, los propios contendientes quienes acogen o rechazan el arreglo. Se trata entonces de mecanismos netamente autocompositivos: el tercero dirimente no impone, sino, simplemente, propone (Jarrosson, 1987).

Por su parte, en el ámbito anglosajón, siendo considerado como el mecanismo de solución de controversias natural de los proyectos de infraestructura, podríamos en términos de Genton (2003) hablar de los denominados dispute boards (DB). Dos de ellos podrían citarse: los dispute resolution boards (DRB) y los dispute adjudication boards (DAB).

En los primeros, un panel dirimente ofrece recomendaciones que, salvo desacuerdo expreso de alguno de los contratantes querellantes, son vinculantes para los pleiteantes. En los segundos, las decisiones del dirimente, que en principio son vinculantes para los contendientes, pueden ser impugnadas ante un tribunal arbitral.

Desde luego, a pesar de las evidentes similitudes terminológicas, entre estas figuras foráneas y la nuestra existe un abismo insoslayable: nuestro amigable componedor impone un arreglo -que no lo propone-. Esta decisión, por lo demás, no está sometida a ninguna condición suspensiva, como la aprobación de las partes. Tampoco, en estricto sentido, tiene una necesaria impugnación ante los tribunales ordinarios o arbitrales. En una palabra, este contrato típico ${ }^{10}$

10 Dotado de un puntual régimen especial jurídico: arts. 59-61 de la Ley 1563 de 2012. colombiano se reconoce como un mecanismo verdaderamente heterocompositivo.

Una vez presentada esta breve panorámica del arbitraje contractual denominado amigable composición nos disponemos a descubrir su naturaleza contractual.

\section{LA NATURALEZA CONTRACTUAL DE LA AMIGABLE COMPOSICIÓN COLOMBIANA}

Según el art. 1501 cc, todos los contratos, sin que importe en cuál ámbito del derecho nos encontremos - público o privado-, tienen tres componentes: elementos que emergen de la esencia de la convención, aquellos que se reconocen como de su naturaleza y aquellos especialmente acuñados por los contratantes -que Andrés Bello calificó como puramente accidentales-.

De acuerdo con los primeros, los elementos de la esencia, se identifica su calificación (cs Civil: 5 jun. 1937, J. Mujica y 13 dic. 2002, C. Jaramillo).

En el caso concreto identificamos una obligación esencial de la amigable composición: la realización de un acto jurídico de transacción. Justamente, este elemento esencial se identifica con el contrato especial ${ }^{11}$ de mandato: la

11 'Los 'contratos especiales' son los más comunes de los contratos, aquellos que son tan utilizados que presentan un carácter repetitivo que ha permitido constituir categorías bien clasificadas. (...) Estas categorías son las diferentes 'especies' que se pueden enumerar dentro del 'genero' constituido por la noción de contrato en general, como acto jurídico" (Bénabent, 2001). Sobre el mandato, véase Gómez (1999). 
gestión que se le confía al mandatario es un negocio o acto jurídico (Cárdenas, 2007). ${ }^{12}$

De manera que tanto el mandato como la amigable composición comparten igual código genético. Los dos convenios descansan sobre un instrumento esencial: la obligación de realizar un acto jurídico por cuenta, en interés de otro. Por consiguiente, los beneficios y perjuicios del acto jurídico encomendado deben ser asumidos por el mandante. ${ }^{13}$

Además, dentro de la estructura del contrato de amigable composición se abre paso otro convenio bien reconocido: la transacción. En efecto, el acto jurídico encargado en la amigable composición es una transacción. Así las cosas, nuestro mecanismo propone o engloba dos contratos yuxtapuestos: el mandato asumido por el componedor y el contrato de transacción.

En una palabra, la normativa de nuestra amigable composición estaría conformada, en primer término, por los tres artículos de la Ley 1563 de 2012 (arts. 59-61) y aquellas relacionadas con el convenio de transacción (arts. 2469-2487 cc).

En segundo término, también serían aplicables las normas sobre el contrato de mandato (para el mandato civil los arts. 2142 a 2199 cc y para el mandato comercial los arts. 1262 a 1286 cco).

12 En el derecho privado colombiano, el mandato tiene, por lo menos, dos regímenes especiales: el mandato civil (arts. 2142 a $2199 \mathrm{cc}$ ) y el mandato comercial (arts. 1262 a 1286 cco). En materia mercantil, también se reconocen algunas variedades, como la comisión, consignación, preposición, etc.

13 En el ámbito anglosajón se hace referencia a la Agency, un vínculo entre una persona denominada principal y otra, conocida como agente, quien debe actuar por aquella. Véase Conviser (2001).
Desde luego, también serían aplicables las disposiciones de los regímenes generales contractuales, comunes a todos los contratos (v. gr. en el cc el libro Cuarto, los títulos I a XXI y en el cco el libro Cuarto, título I, capítulo VI). Por lo demás, si se presentasen lagunas, el operador jurídico podría proponer interpretaciones analógicas.

Una vez presentada esta estructura, procederemos a identificar ciertos rasgos comunes y diferenciales de la amigable composición con los convenios afines.

\section{A. Rasgos comunes con el mandato}

Dos momentos contractuales serán estudiados: la formación y la ejecución de los convenios.

\section{Formación de los convenios}

Como primera medida vale la pena precisar lo siguiente: en la normativa especial de la amigable composición no se establece solemnidad alguna para su perfeccionamiento o formación. ${ }^{14}$ Así las cosas, en principio tendría que reconocerse que tanto la amigable composición como el mandato (arts. 2149 y $2150 \mathrm{cc}$ ) son contratos consensuales. ${ }^{15}$ Incluso, estimamos que, transcurrido un término razonable, el simple silencio

14 Por el contrario, según el art. 52 del Decreto 2279 de 1989 —ya derogado-, el contrato de amigable composición podía considerarse como un arquetipo de mandato solemne, que exigía la forma escrita ad substantiam.

Ya los romanos consideraban que, como la venta, arrendamiento y sociedad, el mandato era un contrato consenso, que no requería ninguna formalidad para su formación. Consúltese al respecto: Arangio-Ruiz (1998) y Gaudemet (1998) 
del amigable componedor puede mirarse como aceptación (art. 2151 cc).

Además, tanto la amigable composición como el mandato están abiertos a cualquier tipo de personas, naturales o jurídicas, públicas o privadas (arts. 59 de la Ley 1563 de 2012 y 2142 y ss. cc). Ahora bien, si en la amigable composición interviene una entidad estatal, tendrá entonces que constar por escrito al estar sujeta a una formalidad ad substantiam actus. Lo anterior teniendo en cuenta lo dispuesto en el artículo 39 de la Ley 80 de 1993.

\section{Ejecución de los convenios}

Como acontece con el mandato (arts. 2157 cc y 1263 cco), el amigable componedor debe ceñirse rigurosamente a los términos del contrato de mandato de amigable composición (art. 61 de la Ley 1563 de 2012). En los dos casos, los mandantes pueden servirse de las estipulaciones que a bien tengan respecto de la manera como se debe ejecutar el contrato de amigable composición.

De igual manera, para los dos contratos se impone la siguiente obligación sobre los mandantes y querellantes: están obligados respecto del mandatario y componedor a proveerlos de lo necesario para la ejecución del encargo (arts. 59 de la Ley 1563 de 2012 y 2184 num. 1 cc).

\section{B. Particularidades de la amigable composición}

Pese a sus parecidos de familia con el mandato, la amigable composición tiene importantes particularidades. Estas peculiaridades se predican tanto para los mandantes-querellantes como respecto del mandatario-componedor.

\section{Sobre los mandantes-querellantes}

Empecemos con la siguiente peculiaridad respecto del mando y respecto de cualquier otro convenio que conozcamos: la amigable composición impone siempre una doble representación de los querellantes en la persona del componedor (CConst., SU-091/00, Á. Tafur).

Así las cosas, es pertinente insistir en lo siguiente: pese a ser su hacedor, el componedor no es parte de la transacción. Los únicos vinculados con ella son los mandantes mismos.

Un asunto muy controversial está relacionado con la revocabilidad del mandato. En efecto, el art. 2189 cc permite la revocación del mandante (Gómez, 1980). ¿Podría extenderse esta instrucción a la amigable composición? Pensamos que esta instrucción tendría que ser relativizada: dado que el encargo emerge de dos mandantes, la revocación exigiría igualmente el consenso entre ambos.

\section{Sobre el mandatario-componedor}

Como primera medida, anotamos que el acto jurídico encargado al componedor es siempre 
una transacción. Esta obligación del componedor, diferenciándose de un mandatario corriente (art. $2155 \mathrm{cc}$ ), podría reconocerse como una obligación de hacer de resultado.

De igual manera, el componedor, a diferencia de cualquier otro mandatario, está obligado a respetar el derecho de defensa de los querellantes a propósito de la imposición de la transacción. ${ }^{16}$

Desde luego, el componedor tampoco asumiría los mismos límites de mandatario ordinario, quien debe abstenerse de concretar un encargo gravemente pernicioso para el mandante (arts. 2175 cc, 1274 y 839 cco).

Tampoco asumiría la prohibición de fungir de contraparte del mandante o contratar a nombre de otra persona (arts. 839 y 1274 cco). Además, el deber de lealtad impuesto al mandatario estándar (art. $2175 \mathrm{cc}$ ) tendría que ser "relativizado" (Malaurie y Aynès, 1997). Por lo demás, el carácter intuitu personae de la amigable composición no permite al componedor la sustitución de su encargo.

Así mismo, en cuanto a la designación del componedor-mandatario, en la normativa se impone su tácita designación por parte de un tercero:

A falta de acuerdo previo entre las partes, se entenderá que se ha delegado la designación a un centro de arbitraje del domicilio de la parte convocada escogido a prevención por la parte convocante (...) De no existir un centro de arbitraje

16 La jurisprudencia propone tres etapas: audiencia de apertura, etapa de investigación y etapa de decisión (CConst., T-015/05, R. Escobar). en el domicilio de la parte convocada, la parte convocante podrá escoger cualquier centro de arbitraje del país para la designación y el procedimiento a seguir a falta de acuerdo expreso (art. 61 de la Ley 1563 de 2012).

Por lo demás, los amigables componedores -si se trata de un cuerpo colegiado-deben realizar su misión de manera coligada (Arrubla, 2013). Al contrario, en el caso del mandato ordinario plural, los mandatarios pueden cumplir su misión de forma separada o independiente, a menos que por una cláusula especial se prohíba expresamente lo contrario (art. $2153 \mathrm{cc}$ ).

Finalmente, respecto de la obligación del componedor, el instrumento de transacción no tiene que incluir las "famosas" concesiones reciprocas de los querellantes, citadas por la jurisprudencia para este tipo de convenios. ${ }^{17}$

Ciertamente, el componedor debe imponer una decisión que cierre una disputa (por ejemplo

17 Sobre la transacción se ha afirmado: "Para que haya transacción, en el sentido estrictamente jurídico del vocablo, requiérese, según los dictados de la jurisprudencia universal, que los contratantes terminen una controversia nacida, o eviten un litigio que está por nacer, mediante el abandono recíproco de una parte de sus pretensiones, o la promesa que una de ellas hace a la otra de alguna cosa para obtener un derecho claro y preciso" (CE Contencioso Administrativa, 21 may. 92, J. Uribe).

En otra sentencia se puede leer lo siguiente: "El contrato de transacción supone como condiciones de su formación: a) el consentimiento de las partes; b) la existencia actual o futura de una desavenencia, disputa o desacuerdo entre las mismas; c) la transacción supone reciprocidad de concesiones o de sacrificios por parte de cada uno de los contratantes. Esta es la circunstancia que distingue la transacción de la simple renuncia de un derecho, de la remisión de una deuda, del desistimiento" (csJ Penal, 30 nov. 2006, M. Pulido).

En la doctrina clásica se encuentra: "En el caso fallado mal podía existir transacción cuando no concurrían ninguna de sus características: no se ponía fin a un litigio pendiente, no se precavía ningún litigio eventual y, por último, tampoco habían concesiones recíprocas de las partes" (Somarriva, 1939). 
respecto de un conflicto de responsabilidad suscitado entre las partes, art. 60 de Ley 1563 de 2012), sin que importen las equivalencias obligacionales de los mandantes (Bénabent, 2001).

Así las cosas, podría pensarse que la decisión impuesta por el componedor, estrictamente hablando, "toma prestados los atavíos de la transacción" con el propósito de alcanzar los efectos "de cosa juzgada en última instancia" (art. $2483 \mathrm{cc})$.

\section{Sobre el desarrollo de la composición}

En primer lugar, la amigable composición tiene que ser acordada en un pacto de composición. Puede tratarse, en este orden de ideas, de un contrato de compromiso de composición o de una cláusula contractual de composición.

Como se verá inmediatamente, la normativa establece una serie de presunciones y reglas supletivas que van a asegurar el feliz término de la composición.

En segundo lugar, el componedor puede imponer su transacción sobre toda suerte de querellas relacionadas con el alcance de las obligaciones derivadas de un negocio jurídico, los incumplimientos contractuales y, en general, cualquier asunto relacionado con la responsabilidad contractual o extracontractual.

En tercer lugar, dado que el componedor puede ser elegido por un tercero, la normativa establece novedosas presunciones. En una palabra, el silencio de las partes frente a la designación del componedor y el procedimiento debe ser suplido por las reglas acuñadas en el art. 60 de la Ley 1563 de 2012.

Por un lado, a falta de acuerdo previo entre las partes respecto del nombre del componedor, se entiende que tal designación ha sido delegada a un centro de arbitraje del domicilio de la parte convocada, escogido a prevención por la parte convocante. Nótese que el legislador, con enorme pragmatismo, se sirve en este caso de la infraestructura de los centros de arbitraje del país. Por lo demás, si no existe un centro de arbitraje en el domicilio de la parte convocada, la convocante puede escoger cualquiera de los que funcionan a nivel nacional.

Por otro lado, en cuanto al procedimiento, se establece una presunción muy similar a la anterior: si no hay acuerdo entre las partes, se entienden acordadas las reglas de procedimiento del centro de arbitraje escogido a prevención por la convocante.

En Colombia, en el caso de los proyectos de infraestructura, la Agencia Nacional de Infraestructura (ANI) ha adoptado en el contrato estándar para la cuarta generación de concesiones algunos modelos de cláusula contractual de composición. En estos modelos las partes acuerdan el procedimiento de designación de árbitros y las reglas de procedimiento. En consecuencia, para estos casos en particular, en principio no operan las reglas supletivas antes mencionadas. A continuación destacaremos los aspectos más relevantes de uno de los modelos 
propuestos por la ANI para las cláusulas de amigable composición a incluir en sus contratos.

En relación con el amigable componedor, en este modelo de cláusula la ANı establece que las partes, al suscribir el contrato, acuerdan acudir a un panel de amigables componedores permanente para definir todas aquellas controversias que expresamente se han señalado en el contrato para conocimiento del amigable componedor. En cuanto a su composición, precisa que el panel estará compuesto por tres personas naturales seleccionadas de conformidad con el siguiente procedimiento: dentro de los diez días calendario siguientes a la fecha de suscripción del contrato de concesión, cada una de las partes elaborará una lista, junto con las respectivas hojas de vida, de cinco profesionales de las siguientes disciplinas: economía, finanzas, ingeniería, arquitectura y áreas afines (no incluye al profesional en derecho que será objeto de un procedimiento especial), que cuenten con una experiencia profesional específica acreditada de ocho años en contratación estatal y/o proyectos de infraestructura, que deberá remitir a la otra parte dentro de dicho término.

Dentro de los cinco días calendario siguientes a la remisión de estas listas la parte contraria seleccionará el miembro de la lista que integrará el panel de amigables componedores y ejercerá las funciones previstas en el contrato por la totalidad del plazo del contrato. Acto seguido remitirá comunicación a su contraparte, así como al profesional designado, informando la selección efectuada.
Así mismo, establece una especie de sanción para la parte que no remita la información dentro de los términos previstos. Esta consiste, en el caso en que no se remitan las listas, en que la parte contraria podrá solicitar la designación de este miembro del panel al Centro de Arbitraje y Conciliación (CAC) de la Cámara de Comercio de Bogotá (ссв). En cuanto a la parte que debe hacer la selección, si no lo hace dentro del término previsto, la parte remitente de la respectiva lista queda habilitada por el contrato para hacer la selección.

En lo que concierne al profesional en derecho, plantea que dentro de los quince días calendario siguientes a la fecha de suscripción del contrato de concesión, las partes remitirán comunicación al cAc de la ccB informándole que delegarán a dicho Centro su elección, mediante sorteo que se realice de las listas allí disponibles y que acrediten una experiencia profesional específica de ocho años en contratación estatal. El procedimiento y tiempos para realizar el sorteo de este miembro del panel de amigable componedor se rige por el reglamento vigente del CAC de la ссв para el mecanismo de amigable composición. No obstante, precisa que las partes, en el sorteo que se realice, podrán tener la opción de rechazar hasta dos designaciones cada una.

Para la conformación del panel de amigables componedores establece un plazo estimado de cuarenta días contados a partir de la suscripción del contrato, y precisa que una vez aceptadas las designaciones de los tres miembros del panel, este dispone de los cinco días siguientes para informar a las partes un lugar 
de funcionamiento y el mecanismo de amigable composición; dentro de los dos días siguientes, los amigables componedores deben hacer una declaración de independencia e imparcialidad respecto de las partes, en la cual manifiesten que no tienen ninguna inhabilidad o incompatibilidad de conformidad con lo exigido por la ley aplicable. En esta misma declaración deben reconocer expresamente que están obligados a conocer en detalle las características del contrato de concesión y de todos sus apéndices, así como las normas nacionales e internacionales que sean aplicables. Igualmente, en la declaración deben reconocer que están en la obligación de conocer detalladamente todos los aspectos de la ejecución del contrato, sus modificaciones y cualquier otro aspecto relevante frente a su desarrollo, de tal manera que estén en capacidad de dar una respuesta rápida e informada en todos los casos que se sometan a su conocimiento.

Prevé este modelo de cláusula que si durante este tiempo alguna de las partes manifiesta por escrito dudas justificadas acerca de la imparcialidad o independencia de algún miembro del panel y su deseo de relevarlo con fundamento en la información suministrada por este, se procederá a su reemplazo.

Un aspecto a destacar en relación con este modelo de cláusula de la ANı, que se aparta de la naturaleza eminentemente contractual de la amigable composición, tiene que ver con el supuesto que se plantea según el cual, si durante el curso del contrato se llegare a establecer que alguno de los integrantes del panel no reveló información que debía suministrar al momento de aceptar el nombramiento, por ese solo hecho quedará impedido, y así deberá declararlo, so pena de ser recusado. En este último caso, los restantes miembros del panel decidirán sobre la separación o continuidad del miembro respectivo. A falta de unanimidad, el miembro respectivo será reemplazado. En todo caso, el impedimento o la recusación del integrante del amigable componedor no afectará la fuerza vinculante de las decisiones adoptadas con anterioridad, salvo con excepción de los casos de nulidad o rescisión.

En caso de sobrevenir un hecho que pudiere generar duda a alguna de las partes sobre la independencia o imparcialidad de un miembro del panel de amigables componedores, el modelo de cláusula señala que este deberá revelarlo a las partes sin demora; si cualquiera de las partes considera que tal circunstancia afecta la imparcialidad o independencia del integrante del panel de amigables componedores, los restantes miembros del panel decidirán sobre el particular. A falta de unanimidad, el miembro respectivo será reemplazado.

Adicionalmente plantea que el panel de amigables componedores permanecerá activo desde el momento de la designación de sus miembros y hasta la fecha en que se suscriba el acta de reversión, y que durante el periodo en que ejerzan sus funciones los integrantes tendrán derecho a percibir remuneración. En todo caso, precisa que no tendrán relación laboral alguna con las partes y que su vinculación al proyecto se enmarca y limita estrictamente a las funciones 
que para la figura del panel de amigables componedores prevé la ley aplicable.

Aclara, adicionalmente, que la designación de los miembros del panel de amigables componedores deberá ratificarse cada dos años por la parte que haya remitido la lista, y que el tercero escogido por sorteo de la lista del CAC de la CCB deberá ratificarse en el mismo término de común acuerdo entre las partes. Si los miembros del panel no fueren ratificados, este modelo de cláusula prevé la realización de una nueva designación de conformidad con el procedimiento antes descrito. Cuando se presente la renuncia o falta de un integrante del panel de amigables componedores, el modelo de cláusula establece que este deberá ser sustituido dentro de los diez días siguientes al recibo de la renuncia de conformidad con la parte o mecanismo que lo designó. Reconoce, de conformidad con lo previsto en el artículo 61 de la Ley 1563 de 2012, que las partes de común acuerdo podrán modificar en cualquier tiempo la forma de designación de los integrantes del panel de amigables componedores y el procedimiento para su funcionamiento.

Precisa que las controversias que surjan entre las partes, sobre las cuales el contrato establezca expresamente la posibilidad de acudir a la figura de la amigable composición, deben ser definidas por los miembros del panel en equidad, de manera vinculante e imparcial. Sin embargo, deja abierta la posibilidad de que las partes puedan someter al amigable componedor cualquier controversia, siempre y cuando exista un acuerdo previo, lo que da vía al pacto de composición.
En lo que se refiere a la remuneración de los integrantes del panel de amigables componedores, por regla general el modelo de cláusula establece que se haga con cargo a la subcuenta MASc del contrato de concesión, la cual se alimenta de los aportes que debe hacer el concesionario. La fiduciaria de forma mensual remite a la ANI y al concesionario la relación de los pagos realizados por concepto del panel de amigables componedores. La remuneración de cada uno de los integrantes del panel de amigables componedores, por lo demás, corresponde a una suma mensual cuantificada y certificada por la interventoría, por valor hora de dedicación invertida en atender los asuntos o controversias del contrato de concesión.

En lo que se refiere al procedimiento para la amigable composición, señala que este se iniciará y tramitará de conformidad con el reglamento del CAC de la ccB relativo a la amigable composición o con el reglamento que las partes adoptaren por escrito de común acuerdo en cualquier momento de la ejecución del contrato. La decisión, una vez adoptada, será irrevocable. El panel de amigables componedores tiene un plazo máximo de treinta días hábiles para definir la controversia, los cuales se empiezan a contar a partir del día siguiente a la formulación de esta; si se vence el plazo sin haber llegado a una decisión, pierde competencia para resolver la controversia específica, y esta podrá ser sometida por cualquiera de las partes a un tribunal de arbitramento. Sin embargo, el plazo para decidir podrá ampliarse a solicitud del panel, siempre que esa solicitud sea aceptada por las partes. 
El modelo de cláusula deja en cabeza del panel de amigables componedores el deber de informar a la Procuraduría General de la Nación y a la Agencia Nacional de Defensa Jurídica del Estado sobre la apertura de cada proceso de amigable composición, para efectos de lo previsto en el artículo 49 de la Ley 1563 de 2012. En estos casos, de ser necesario, pueden suspenderse los términos para tomar la decisión. En todo caso, precisa que el inicio del procedimiento de amigable composición no faculta a las partes para suspender unilateralmente la ejecución de las obligaciones del contrato, como tampoco inhibe el ejercicio de las facultades ajenas al derecho común y las excepcionales con las que cuenta la ANI.

En cuanto al alcance y contenido de las decisiones que adopte el panel de amigables componedores, el modelo de cláusula señala que se circunscribirá a lo expresamente previsto en la ley aplicable; que serán motivadas y dejarán constancia de la manera como se estableció la intención de los contratantes para su adopción en los términos del artículo 1618 cc y la forma como en aplicación de la equidad se procedió a determinar el alcance o forma de cumplimiento de las obligaciones derivadas de un negocio jurídico, a determinar la existencia o no de un incumplimiento contractual y a decidir sobre conflictos de responsabilidad suscitados entre las partes, entre otras determinaciones, en aplicación del artículo 60 de la Ley 1563 de 2012. En cuanto a las restricciones, el panel de amigables componedores no tiene competencia para conocer las controversias que se deriven del ejercicio de las facultades ajenas del derecho común, ni de las facultades exorbitantes de que goza la ANI.

El modelo de cláusula expresamente señala que las decisiones del panel de amigables componedores deben adoptarse por unanimidad. Si la decisión no es unánime, no será vinculante ni de obligatorio cumplimiento y cualquiera de las partes podrá plantear la disputa ante un tribunal de arbitramento. Por otra parte, establece que solo en los casos en que se refieran a una eventual causal de nulidad o rescisión de la decisión, las decisiones del panel de amigables componedores que definan la controversia pueden ser sometidas al conocimiento de la jurisdicción arbitral, de conformidad con lo establecido en la ley aplicable.

\section{CONCLUSIONES}

La amigable composición es un contrato especial: una institución social creada por una comunidad y estructurada a través de normas, con el propósito de cumplir con funciones de organización -especialmente, regular la solución de toda suerte de controversias-. A partir de una discreta reseña normativa (arts. 59, 60 y 61 de la Ley 1563) el convenio se nos presenta como una variedad del contrato de mandato con representación (arts. 2142 y 2177 cc).

En una palabra, la operación engloba un contrato de mandato y un convenio de transacción. En cuanto al mandato, una de las partes, el amigable componedor, impone una transacción al otro extremo contractual: los mandantes-querellantes. Así las cosas, cuando la gestión del com- 
ponedor concluye, se nos revelan dos contratos yuxtapuestos: el mandato de amigable composición y la decisión con fuerza de transacción.

Así mismo, resulta de extrema importancia agregar lo siguiente: la amigable composición es un mandato sui generis. Está dotado, en efecto, de un régimen especial propio. Incluso, asuntos tales como la designación del componedor y el procedimiento aplicable son abordados por el legislador a través de una novedosa normativa supletiva.

Por todo lo anterior, en el marco de los proyectos de infraestructura que se desarrollan actualmente en Colombia, la amigable composición se constituye en una alternativa eficiente y de bajo costo, que permite que las partes puedan resolver de manera directa las complejidades propias de este tipo de operaciones y lleguen, por regla general, a una solución definitiva sin que se presente un enfrentamiento abierto que pueda afectar en el mediano y largo plazo su relación comercial y, por ende, la ejecución del contrato.

\section{Referencias}

1. Arangio-Ruiz, V. (1998). Istituzioni di diritto romano. Napolés: Casa Editrice Dott Eugenio Jovene.

2. Arrubla, J. (2013). Contratos mercantiles. Contratos típicos. Bogotá: Legis/Pontificia Universidad Javeriana.
3. Blanco Carrasco, M. (2009). Mediación y sistemas alternativos de solución de conflictos. Una visión jurídica. Madrid: Reus.

4. Bénabent, A. (2001). Droit Civil. Les contrats spéciaux civils et commerciaux. París: Montchrestien.

5. Cárdenas, J. (2007). El mandato y la representación. En F. Mantilla y F. Ternera (Coords.), Los contratos en el derecho privado. Bogotá: Legis/Universidad del Rosario.

6. Código Civil colombiano.

7. Código de Comercio colombiano.

8. Consejo de Estado, Sala de lo Contencioso Administrativo, Sección Tercera. Sentencia del 21 de mayo de 1992 (C. P.: Julio C. Uribe Acosta).

9. Consejo de Estado, Sala de lo Contencioso Administrativo, Sección Tercera. Sentencia del 6 de febrero de 1998 (C. P.: Daniel Suárez Hernández).

10. Consejo de Estado, Sala de Consulta y Servicio Civil. Sentencia del 13 de agosto de 2009 (C. P.: Enrique José Arboleda Perdomo).

11. Constitución de Mariquita. (1815).

12. Constitución de Neiva. (1815).

13. Constitución Política de Colombia. (1991). 
14. Conviser, R. J. (2001). Gilbert Law Summaries: Agency, Partnership, \& Limited Liability Companies. New York: Harcourt Legal \& Professional Pubns.

15. Corte Constitucional de Colombia. Sala Plena. Sentencia C-478 de 1998 (M. P.: Humberto Sierra Porto, septiembre 9 de 1998).

16. Corte Constitucional de Colombia. Sala Plena. Sentencia SU-091 de 2000 (M. P.: Álvaro Tafur Galvis, febrero 2 de 2000).

17. Corte Constitucional de Colombia. Sala Plena. Sentencia C-098 de 2001 (M. P.: Martha Victoria Sáchica Méndez, enero 31 de 2001).

18. Corte Constitucional de Colombia. Sala Quinta de Revisión de Tutelas. Sentencia T-015/05 (M. P.: Rodrigo Escobar Gil, marzo 5 de 2005).

19. Corte Constitucional de Colombia. Sala Séptima de Revisión de Tutelas. Sentencia T-153/10 (M. P.: Jorge Ignacio Pretelt Chaljub, marzo 5 de 2010).

20. Corte Suprema de Justicia. Sala de Casación Civil. Sentencia del 5 de junio de 1937. (M. P.: Juan Mujica).

21. Corte Suprema de Justicia. Sala de Casación Civil. Sentencia del 13 de diciembre de 2002. (M. P.: Carlos I. Jaramillo).
22. Corte Suprema de Justicia. Sala de Casación Penal Sentencia del 30 de noviembre de 2006 (M. P.: Marina Pulido de Barón).

23. De Sola Cañizares, F. (1962). Tratado de derecho comercial comparado. Barcelona: Montaner y Simón.

24. Díez-Picazo, L. (1957). El arbitrio de un tercero en los negocios jurídicos. Barcelona: Bosch.

25. Gaviria, E. (1987). Lecciones de derecho comercial. Medellín: Diké.

26. Gaudemet, J. (1998). Droit privé romain. Paris: Montchrestien.

27. Genton, P. (2003). Dispute Boards' part 7 of Bernstein's Handbook of Arbitration and Dispute Resolution Practice. Londres: Sweet \& Maxwell.

28. Gómez, C. (1999). De los principales contratos civiles. Bogotá: Editorial Temis.

29. Gómez, J. (1980). Contratos comerciales. Bogotá: Kelly.

30. Guasch, L. (2004). Granting and Renegotiation Infrastructure Concessions: Doing it Right(C 2004. Washington: The International Bank for Reconstruction and Development/The World Bank.

31. Jaramillo, C. (1998). Solución alternativa de conflictos en el seguro y en el reaseguro. Bogotá: Pontificia Universidad Javeriana. 
32. Jarrosson, C. (1987). La notion d'arbitrage. Paris: Librairie générale de droit et de jurisprudence.

33. Lardé, J. y Sánchez, R. (2014). La brecha de infraestructura económica y las inversiones en América Latina. Boletín de la Cepal, 332(4).

34. Ley 105 de 1890. Sobre reformas a los procedimientos judiciales. Noviembre 24 de 1890.

35. Ley 105 de 1931. Sobre organización judicial y procedimiento civil. Octubre 17 de 1931. DO n. ${ }^{\circ} 21823$.

36. Decreto-Ley 1400 de 1970. Por el cual se expide el Código de Procedimiento Civil. Agosto 6 de 1970. DO n. ${ }^{\circ} 39013$.

37. Decreto 2279 de 1989. Por el cual se implementan sistemas de solución de conflictos entre particulares y se dictan otras disposiciones. Octubre 7 de 1989. DO n. ${ }^{\circ}$ 39012.

38. Ley 80 de 1993. Por la cual se expide el Estatuto General de Contratación de la Administración Pública. Octubre 28 de 1993.

39. Ley 446 de 1998. Por la cual se adoptan como legislación permanente algunas normas del Decreto 2651 de 1991, se modifican algunas del Código de Procedimiento Civil, se derogan otras de la Ley 23 de 1991 y del Decreto 2279 de 1989, se modifican y expiden normas del Código Contencioso Ad- ministrativo y se dictan otras disposiciones sobre descongestión, eficiencia y acceso a la justicia. Julio 7 de 1998.

40. Ley 550 de 1999. Por la cual se establece un régimen que promueva y facilite la reactivación empresarial y la reestructuración de los entes territoriales para asegurar la función social de las empresas y lograr el desarrollo armónico de las regiones y se dictan disposiciones para armonizar el régimen legal vigente con las normas de esta ley. Diciembre 30 de 1999. DO n. ${ }^{\circ} 43836$.

41. Ley 1508 de 2012. Por la cual se establece el régimen jurídico de las Asociaciones Público Privadas, se dictan normas orgánicas de presupuesto y se dictan otras disposiciones. Enero 10 de 2012. DO n. ${ }^{\circ} 48308$.

42. Ley 1563 de 2012. Por medio de la cual se expide el Estatuto de Arbitraje Nacional e Internacional y se dictan otras disposiciones. Julio 12 de 2012. DO n. ${ }^{\circ} 48489$.

43. Ley 1682 de 2013. Por la cual se adoptan medidas y disposiciones para los proyectos de infraestructura de transporte y se conceden facultades extraordinarias. Noviembre 22 de 2013.

44. Ley 1742 de 2014. Por la cual se adoptan medidas y disposiciones para los proyectos de infraestructura de transporte, agua potable y saneamiento básico, y los demás sectores que requieran expropiación en proyectos de inversión que adelante el Estado 
y se dictan otras disposiciones. Diciembre 26 de 2014.

45. Malaurie, Ph. et Aynès, L. (1997). Les contrats spéciaux. Paris: Cujas.

46. Restrepo Piedrahita, C. (1996). Primeras constituciones de Colombia y Venezuela 1811-1830. Bogotá: Universidad Externado de Colombia.

47. Somarriva, M. (1939). Las obligaciones y los contratos ante la jurisprudencia. Santiago: Editorial Nascimento.
48. Vasallo Magro, J. e Izquierdo de Bartolomé, R. (2010). Infraestructura pública e inversión privada: conceptos y experiencias en América y España. Bogotá: CAF.

49. Venegas, A. (2005). Arbitraje y derecho de reaseguros. En E. Silva, y F. Mantilla, (Coords.), El contrato de arbitraje. Bogotá: Legis.

50. Zimmermann, R. (1996). The law of obligations. Roman foundations of the civilian tradition. Oxford: Oxford University Press. 